\title{
ASSESSMENT OF IMPACT OF THE SOLAR I OIL SPILL ON THE INFAUNAL ASSEMBLAGES OF SOUTHERN GUIMARAS, PHILIPPINES
}

\author{
Annabelle G.C. del Norte-CAMPOS ${ }^{1, *}$ and Erma Narida-Nacionales ${ }^{2}$ \\ ${ }^{1}$ Marine Biology Laboratory, Division of Biological Sciences, College of Arts \& Sciences \\ University of the Philippines in the Visayas \\ ${ }^{2}$ Southern Iloilo Polytechnic College-WVSCT, Miagao, Iloilo \\ *e-mail: upvmarbio@yahoo.com
}

\begin{abstract}
The study was conducted between September and October 2006 in various sites both inside and outside the Taklong Island National Marine Reserve (TINMAR), southern Guimaras, Philippines, to immediately conduct a rapid 3-month assessment of the impact of the Solar I oil spill incident which occurred in August 11, 2006 in southern Guimaras. The assessment was made possible by the availability of baseline (pre-spill) data which were compared with the present data (post-spill). Results showed the drastic decrease in overall mean densities (no. $\mathrm{m}^{-}$ ${ }^{2}$ ) and species richness in the infaunal assemblages within TINMAR in September 2006, or 1 month after the oil spill. In October 2006 however, a slight increase in both of these parameters was observed, albeit not significant. The decrease is taken as a disturbance, directly resulting from the oil spill. On the other hand, it is not clear at this time if the increase is the start of recovery in the infauna. Our results indicate the need for a continuous monitoring, to allow more definitive conclusions on a) whether the assemblages are recovering, and if indeed they are, b) how long this recovery will take place.
\end{abstract}

Keywords: Infauna, Macrobenthos, Oil spill, Impact assessment, Guimaras

\section{INTRODUCTION}

The MT Solar 1 spilled 2 million liters of bunker fuel on August 11, 2005 in southern Guimaras, Philippines when it sank in the area. A rapid assessment was thus needed to determine its immediate, as well as long-term impacts not only on the habitats, but more especially on the organisms that thrive in these habitats. Invertebrate communities exhibit a wide range of responses to oil, from the most obvious mortalities to sub-lethal impacts, such as physiological, carcinogenic and cytogenetic effects (Suchanek, 1993).

The infauna are animals that live within the sediment (Barnes and Hughes, 1982). They are further categorized into size groupings of mega-, macro- and meiofauna. The macrofauna or those retained by the sieves with a mesh size of $500 \mu \mathrm{m}$, include the polychaetes, bivalves, amphipods, decapod crustaceans, holothurians, and burrowing sea anemones (Gray, 1981). Those inhabiting soft-stratum areas are usually considered very susceptible to oil pollution (Sanborn, 1977).

The aim of this study was to characterize the immediate impact of the Solar I oil spill pollution on the macrofauna of southern Guimaras, west central Visayas, Philippines. This was achieved through: a) temporal comparison (pre-spill vs. post-spill data), both within the Taklong Island National Marine Reserve (TINMAR), and b) spatial comparison (inside TINMAR vs. outside TINMAR). Comparisons were confined to mean species density and species richness of the macrofauna.

\section{MATERIALS AND METHODS}

\section{Temporal comparison}

Sampling for benthic infauna was conducted in September and October 2006, in a total of 14 stations (Fig. 1), all located inside the Taklong 
Island National Marine Reserve (TINMAR), southern Guimaras, Philippines. Infauna samples were collected using a corer (area $=47.78 \mathrm{~cm}^{2}$ ) pushed into the sediment to a depth of $10 \mathrm{~cm}$. Collected samples were preserved in $10 \%$ seawater-formalin stained with Rose Bengal dye. These were brought to the laboratory for processing. In the lab, the sediment samples were sieved in a $500 \mu \mathrm{m}$ mesh, to separate the macrofauna. The macrofauna were sorted out and identified. Polychaetes were identified, whenever possible, down to the species level using literature, such as Fauvel (1953), Fauchald (1977) and Higgins and Thiel (1988). The rest of the macrofauna were identified only up to the class or family level. Density of each taxon was expressed in no. inds. $\mathrm{m}^{-2}$. Species richness was likewise computed, simply as the number of species/station. Present results were compared with baseline information from TINMAR collected in 2002 (Narida-Nacionales and Campos, 2004). One-way ANOVA was performed to test the significance of differences in mean density and species richness between sampling dates.

Sediment samples were sieved through a series of mesh screens with sizes $2000,1800,500,250$,

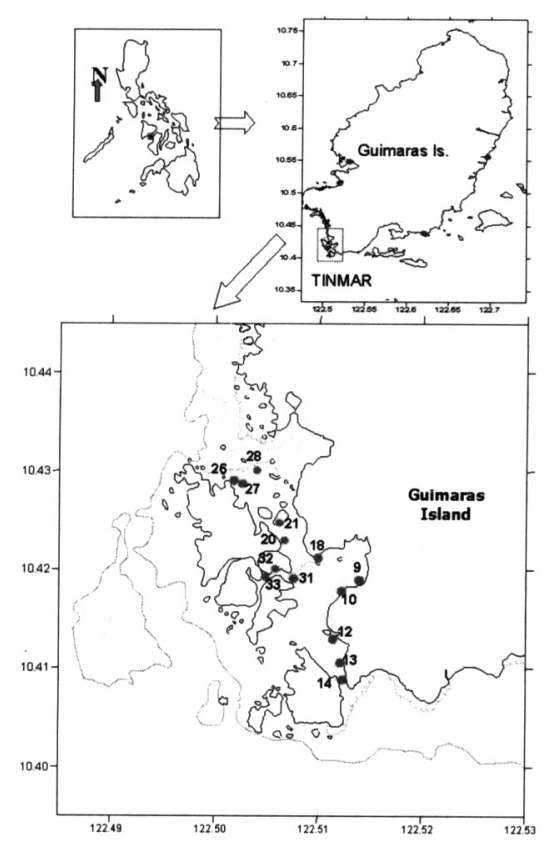

Figure 1. Station locations of the benthic community survey within Taklong Island National Marine Reserve (TINMAR), Guimaras, Philippines. Numbers follow the station numbersin Nacionales and Campos (2004).

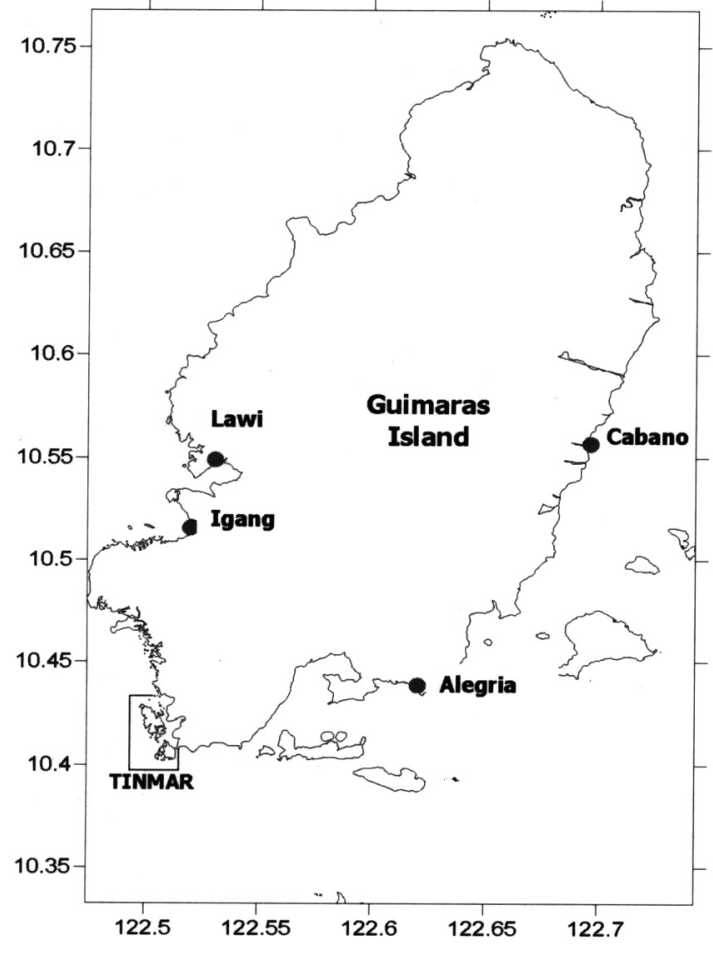

Figure 2. Location of stations sampled outside TINMAR in October 2006.

125, and $63 \mathrm{ì} \mathrm{m}$. The classified particle sizes were oven dried at $110^{\circ} \mathrm{C}$ for $24 \mathrm{hrs}$ and weighed using an analytical balance. Median particle diameter (mid-phi) was estimated by plotting the \% cumulative dry weight versus the corresponding phi value of sieve mesh sizes. Values corresponding to a $\%$ cumulative weight of $50 \%$ correspond to mid $\Phi$ (Gray, 1981). The Sorting Index (SI) was computed according to the formula:

$$
(\Phi 84-\Phi 16) / 4+(\Phi 95-\Phi 5) / 6.6
$$

also referred to as the Inclusive Graphic Standard Deviation of Gray (1981). The index produces the following sediment sorting classes:
Sorting Index Sorting Class
Under $0.35 \Phi$ Very well sorted
0.35-0.50 $\Phi \quad$ Well sorted
0.50-0.71 $\Phi \quad$ Moderately well sorted
0.71-1.00 $\Phi \quad$ Moderately sorted
1.00-2.00 $\Phi \quad$ Poorly sorted
2.00-4.00 $\Phi$ Very poorly sorted
Over $4.00 \Phi \quad$ Extremely poorly sorted 


\section{Spatial comparison}

Benthic infauna were sampled in 4 stations outside TINMAR (Fig. 2). Two of these (Cabano and Alegria) are located in southeast Guimaras, while the other two (Igang and Lawi) are just north of the TINMAR stations. In all four stations, sampling procedures and analyses were similar to the above.

\section{RESULTS AND DISCUSSION}

\section{Temporal comparison}

There was a drastic decrease in terms of overall mean density $\left(\right.$ no. $\mathrm{m}^{-2}$ ) of the macrobenthic fauna in TINMAR between the years 2002 and the present (Table 1). This decrease was likewise found to be significant $(\mathrm{F}=4.612 ; \mathrm{p}<0.05)$. Mean density decreased by more than half $(57.8 \%)$ from September $2002\left(35,768.4\right.$ ind. $\left.\mathrm{m}^{2}\right)$ to September $2006\left(15,182.31\right.$ ind. $\left.\mathrm{m}^{-2}\right)$ (Fig. 3). This trend is duplicated in terms of species richness, i.e. a decrease was observed in September 2006 relative to September 2002 (Table 2 \& Fig. 4). There was however an observed slight increase (17,512.67 ind. $\mathrm{m}^{2}$ ) in the mean densities in the 14 stations in the month of Oct 2006. This increase was however not significant

The decrease in both density and species richness are signs of disturbance to the macrobenthic community brought about by the Solar I oil spill. Hall (1994) defined disturbance as "any discrete event in time that disrupts an ecosystem, community or population structure and changes resources, substrate availability, or the physical environment". The recent oil spill incident qualifies as a good source of disturbance to the macrobenthos, abundance, diversity and number of taxa being good indicators of infaunal health (NOAA, 1997). However, whether the slight increase in mean densities and species richness in October 2006 indicates recovery remains to be seen, as recovery means "the return of an ecosystem to a point within the limits of the natural variability of the system's original functional and structural conditions (Ganning et al., 1984).

A comparison of the relative $\%$ composition of the top 20 macrobenthic taxa is further shown in Table 3. Changes in species/taxa importance can be noted. For example: among the crustaceans, tanaid shrimps which were second in importance in 2002 disappeared in both sampling dates 2006; highly important amphipods in 2002 on the other hand, were absent in September 2006, but were again present in October 2006. In all sampling occasions however, the polychaete and nematode

Table 1. Comparison of the mean density (no. inds.m $\left.{ }^{2}\right)$ of macrobenthic infauna within TINMAR between 2002 (pre-oil spill) and 2006 (postoil spill).

\begin{tabular}{|c|c|c|c|}
\hline Station & Sep-02 & Sep-06 & Oct-06 \\
\hline 10 & 59235.8 & 7236.9 & 7675.5 \\
\hline 31 & 95764.2 & 35307.3 & 22149.3 \\
\hline 33 & 49856.6 & 9868.5 & 14035.2 \\
\hline 18 & 27330.6 & 10526.4 & 21930.0 \\
\hline 21 & 10443.4 & 10965.0 & 15789.6 \\
\hline 20 & 4977.3 & 23026.5 & 19079.1 \\
\hline 9 & 25775.2 & 1535.1 & 16886.1 \\
\hline 32 & 14808.9 & 23903.7 & 15131.7 \\
\hline 12 & 9625.8 & 6579.0 & 21930.0 \\
\hline 13 & 14043.0 & 9649.2 & 20175.6 \\
\hline 14 & 13328.1 & 21491.4 & 26316.0 \\
\hline 26 & 29124.3 & 29605.5 & 32675.7 \\
\hline 27 & 47882.3 & 7675.5 & 1973.7 \\
\hline 28 & 98561.8 & ---- & 9429.9 \\
\hline$n$ & 14 & 13 & 14 \\
\hline Mean & 35768.4 & 15182.3 & 17512.7 \\
\hline$s d$ & 30811.3 & 10281.5 & 7855.3 \\
\hline Median & 26552.9 & 10526.4 & 17982.6 \\
\hline Max & 98561.8 & 35307.3 & 32675.7 \\
\hline Min & 4977.3 & 1535.1 & 1973.7 \\
\hline$F$ & 4.612 & & \\
\hline$P$-value & 0.016 & & \\
\hline
\end{tabular}

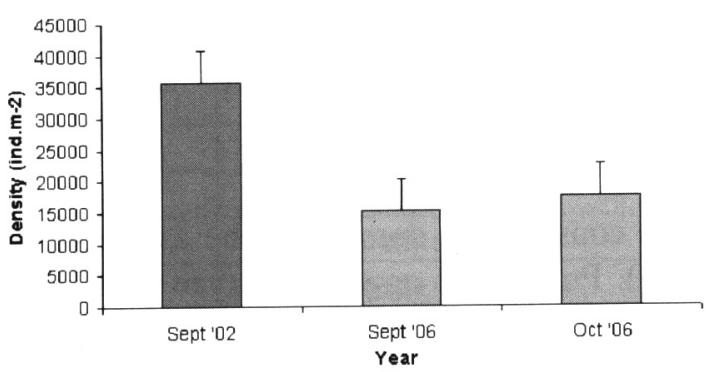

Figure 3. Comparison of mean densities (no. inds. $\mathrm{m}^{-2}$ ) between baseline/pre-spill (Sept.'02) and post-spill (Sept. \& Oct. '06) of macrobenthic fauna within TINMAR. 
Table 2. Comparison of the mean species richness of macrobenthic infauna within TINMAR between 2002 (pre-oil spill) and 2006 (post- oil spill)

\begin{tabular}{|c|c|c|c|}
\hline Station & Sep-02 & Sep-06 & Oct-06 \\
\hline 10 & 50 & 10 & 20 \\
\hline 31 & 41 & 24 & 18 \\
\hline 33 & 35 & 16 & 13 \\
\hline 18 & 47 & 15 & 30 \\
\hline 21 & 40 & 18 & 32 \\
\hline 20 & 35 & 24 & 29 \\
\hline 9 & 55 & 5 & 21 \\
\hline 32 & 14 & 24 & 19 \\
\hline 12 & 12 & 13 & 32 \\
\hline 13 & 37 & 17 & 34 \\
\hline 14 & 29 & 14 & 33 \\
\hline 26 & 24 & 21 & 21 \\
\hline 27 & 16 & 13 & 6 \\
\hline 28 & 19 & -- & 14 \\
\hline$n$ & 14 & 13 & 14 \\
\hline Mean & 32.4 & 16.5 & 23.0 \\
\hline$s d$ & 13.83 & 5.77 & 8.75 \\
\hline Median & 35 & 16 & 21 \\
\hline Max & 55 & 24 & 34 \\
\hline Min & 12 & 5 & 6 \\
\hline$F$ & 8.551 & & \\
\hline$P$-value & 0.001 & & \\
\hline
\end{tabular}

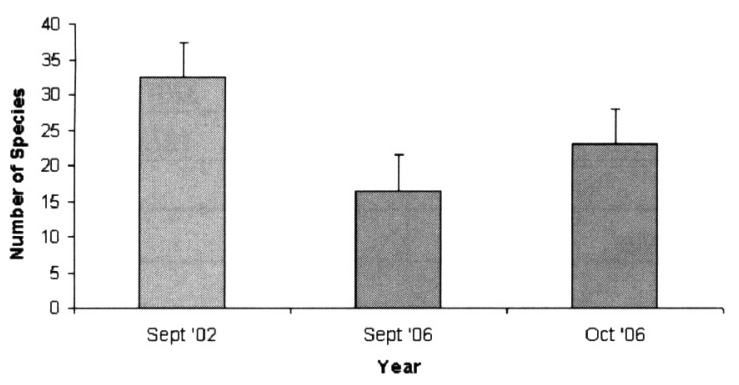

Figure 4. Comparison of mean species richness between baseline/pre-spill (Sept '02) and postspill (Sept. \& Oct. '06) of macrobenthic fauna within TINMAR

worms consistently dominated the assemblages (Fig. 5). Polychaete eggs and larvae were even observed in 4 of the 14 sampled stations (Fig. 6). The changes observed in species composition (Table 3) further represent evidences of the extent of impact of the oil spill. Observed changes in crustacean importance are in agreement with Kingston et al. (1995) whose work in relation to the Braer oil tanker wreck, reported that in general,

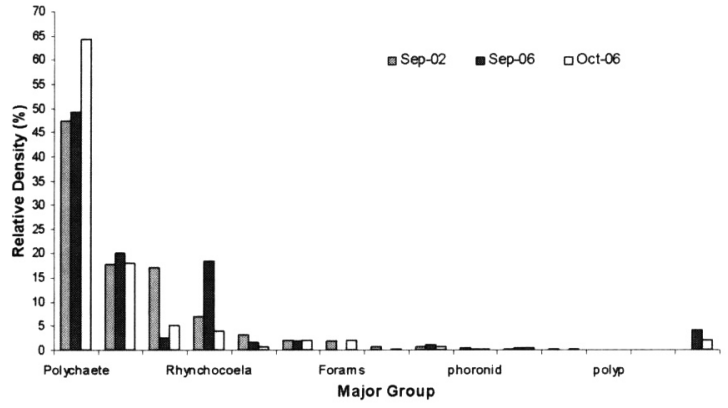

Figure 5. Major groups of macrobenthic fauna within TINMAR in 2002 \& 2006

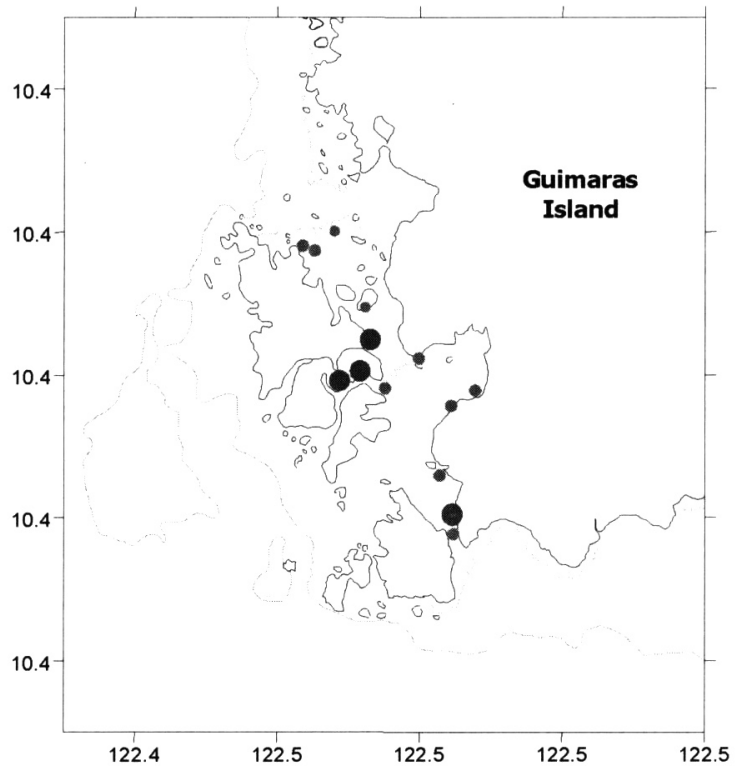

Figure 6. Locations of stations showing presence of polychaete eggs and larvae (blue dots) in Oct. 2006 (red dots indicate absence).

crustaceans have been found to be sensitive to oil spills. This may explain the disappearance of amphipods in September 2006. Although in both years, polychaetes and nematodes remained to be the dominants in the assemblages (Fig. 5), this dominance was further highlighted after the spill by the decrease in richness of other species/ groups. Conan (1982) similarly reported in relation to the Amoco Cadiz oil spill that while limpets and bivalves were immediately affected, polychaetes and large crustaceans were less affected. Polychaetes have also been further reported as rstrategists or opportunistic species (Grassle and Grassle, 1974; Pearson and Rosenberg, 1978; Gray and Pearson, 1982), also consistent with the observed presence of eggs and larvae in Oct. 2006 
Table 3. Species composition of top 20 macrobenthic fauna within TINMAR between $2002 \& 2006$

\begin{tabular}{|c|c|c|c|c|c|}
\hline \multicolumn{2}{|l|}{ Sep-02 } & \multicolumn{2}{|l|}{ Sep-06 } & \multicolumn{2}{|l|}{ Oct-06 } \\
\hline Species Composition & $\%$ & Species Composition & $\%$ & Species Composition & $\%$ \\
\hline Nematode & 17.82 & Nematode & 20.0 & Nematode & 17.98 \\
\hline Tanaid & 9.06 & Rhynchocoela & 18.6 & Dasybranchus sp. & 15.21 \\
\hline Exogone dispar & 8.47 & Exogone dispar & 8.9 & Aricidia quadrilobata & 6.26 \\
\hline Rhynchocoela & 6.98 & Magelona sp. & 6.3 & Exogone dispar & 4.29 \\
\hline Potamilla sp. & 3.81 & Priapulid & 4.1 & Paraonis sp. & 3.94 \\
\hline Amphipod & 3.36 & Lysaretidae & 3.9 & Rhynchocoela & 3.85 \\
\hline Bivalve & 3.35 & Paraonis sp. & 3.8 & Aricidia catherinae & 3.85 \\
\hline Lysaretidae & 2.39 & Aricidia catherinae & 3.7 & Magelona sp. & 3.49 \\
\hline Dasybranchus sp. & 2.21 & Aricidia quadrilobata & 2.6 & Pionosyllis sp. & 2.15 \\
\hline Typosyllis sp. & 2.20 & Crustaceans & 2.6 & Syllis sp. & 2.15 \\
\hline Gastropod & 2.14 & Syllis sp. & 2.3 & Gastropod & 2.15 \\
\hline Magelona sp. & 1.88 & Gastropod & 1.8 & Notomastus sp. & 2.06 \\
\hline Harpacticoid & 1.86 & Bivalve & 1.6 & Priapulid & 2.06 \\
\hline Fabricia sp. & 1.77 & Protodorvillea sp. & 1.4 & Ancistrosyllis sp & 1.79 \\
\hline Notomastus sp. & 1.49 & Ancistrosyllis sp & 1.2 & Capitella sp. & 1.70 \\
\hline Polydora sp. & 1.35 & Pionosyllis sp. & 1.1 & Lysaretidae & 1.52 \\
\hline Eusyllis sp. & 1.29 & Tharyx sp. & 1.1 & Amphipod & 1.43 \\
\hline Aricidia catherinae & 1.14 & Sipunculid & 1.1 & Peneroplis sp. & 1.25 \\
\hline Protodorvillia sp. & 1.13 & Fabricia sp. & 1.0 & Pisionidae & 0.98 \\
\hline Poriferans & 0.98 & Mediomastus sp. & 1.0 & Protodorvillea sp. & 0.98 \\
\hline
\end{tabular}

(Fig. 6). These eggs and larvae were so far, found in the more-sheltered areas of TINMAR that typically have poorly to very poorly sorted sediments (Stations 13, 20, $32 \& 33$ as shown in Table 4). The occurrence of these eggs and larvae suggest recruitment, and therefore as indicated above, the higher possibility of recovery.

\section{Spatial Comparison}

Mean benthic densities in the stations outside TINMAR were highest in Cabano at 14,035.2 inds. $\mathrm{m}^{-2}$, while it was lowest in Lawi $(3,874.3$ ind. $\mathrm{m}^{-2}$ ) in October 2006 (Table 5; Fig. 7).

Table 4. Mid phi $(\phi)$, sediment type, sorting index (SI) and sorting class of the 14 stations sampled inside TINMAR in Sept-Oct 2006

\begin{tabular}{|c|c|c|c|c|}
\hline Station & Mid phi & Sediment type & SI & Sorting class \\
\hline 9 & 2.72 & medium sand & 1.62 & poorly sorted \\
\hline 10 & 2.76 & medium sand & 1.68 & poorly sorted \\
\hline 12 & 0.51 & very coarse sand & 2.22 & very poorly sorted \\
\hline 13 & 1.31 & coarse sand & 1.95 & poorly sorted \\
\hline 14 & 1.60 & coarse sand & 1.68 & poorly sorted \\
\hline 18 & 1.36 & coarse sand & 1.85 & poorly sorted \\
\hline 20 & 1.16 & coarse sand & 1.99 & poorly sorted \\
\hline 21 & 1.66 & coarse sand & 1.77 & poorly sorted \\
\hline 27 & 1.67 & coarse sand & 2.06 & very poorly sorted \\
\hline 28 & 1.39 & coarse sand & 1.66 & poorly sorted \\
\hline 31 & 1.17 & coarse sand & 1.9 & poorly sorted \\
\hline 32 & 1.68 & coarse sand & 1.61 & poorly sorted \\
\hline 33 & 1.63 & coarse sand & 1.73 & poorly sorted \\
\hline
\end{tabular}


Table 5. Comparison of the mean density of macrobenthic infauna in Guimaras Island, October 2006

\begin{tabular}{|c|c|c|c|c|c|}
\hline Station & Cabano & Alegria & lgang & Lawi & TINMAR \\
\hline 1 & 23245.8 & 4605.3 & 5921.1 & 5921.1 & -- \\
\hline 2 & 5482.5 & 12061.5 & 5701.8 & 1973.7 & -- \\
\hline 3 & 13377.3 & 3728.1 & --- & 3728.1 & --- \\
\hline 10 & -- & --- & --- & --- & 7675.5 \\
\hline 31 & --- & --- & --- & --- & 22149.3 \\
\hline 33 & -- & --- & --- & --- & 14035.2 \\
\hline 18 & --- & --- & --- & -- & 21930 \\
\hline 21 & --- & --- & --- & -- & 15789.6 \\
\hline 20 & --- & -- & -- & -- & 19079.1 \\
\hline 9 & --- & --- & -- & -- & 16886.1 \\
\hline 32 & --- & -- & --- & --- & 15131.7 \\
\hline 12 & --- & --- & --- & --- & 21930 \\
\hline 13 &.-- & --- & --- & --- & 20175.6 \\
\hline 14 & --- & --- & --- & --- & 26316 \\
\hline 26 & --- & --- & -- & --- & 32675.7 \\
\hline 27 & -- & -- & -- & -- & 1973.7 \\
\hline 28 & --- & -- & -- & --- & 9429.9 \\
\hline$n$ & 3 & 3 & 2 & 3 & 14 \\
\hline Mean & 14035.2 & 6798.3 & 5811.45 & 3874.3 & 17512.67 \\
\hline sd & 8899.906 & 4579.118 & 155.0685 & 1977.757 & 7855.273 \\
\hline Median & 13377.3 & 4605.3 & 5811.45 & 3728.1 & 17982.6 \\
\hline Max & 23245.8 & 12061.5 & 5921.1 & 5921.1 & 32675.7 \\
\hline Min & 5482.5 & 3728.1 & 5701.8 & 1973.7 & 1973.7 \\
\hline $\mathrm{F}$ (variance) & 746.02 & \multicolumn{4}{|c|}{ on log-transformed data } \\
\hline$P(F<=f)$ one-tail & 0.026 & & & & \\
\hline
\end{tabular}

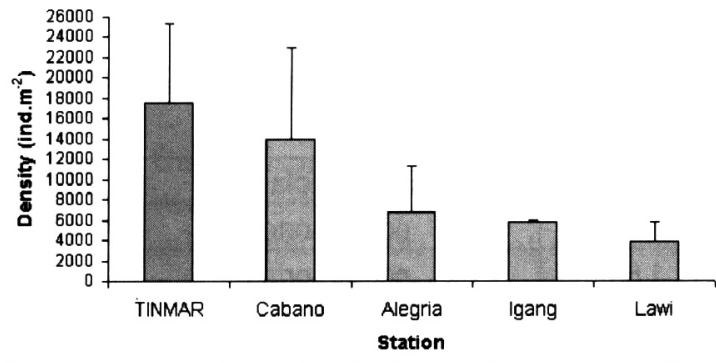

Figure 7. Spatial distribution of mean density of macrobenthic infauna in Guimaras Island, October 2006

Compared with TINMAR, these values are all lower than those of TINMAR stations. The same trends were observed with regards to species richness (Table 6; Fig. 8). Although this would indicate a similar extent of impact with the TINMAR stations, the lack of baseline information precludes definite conclusions. The effects of oil on the infauna are after all, both direct and indirect (NOAA, 1998). Direct effects cause mortalities due to the smothering or toxic effects of oil, whereas indirect/subtle effects are those involving changes in behavior, thus allowing predation (Pearson et al., 1981), as well as effects on reproduction, growth and recruitment.

The study showed that mean densities and species richness of infauna within the TINMAR drastically decreased after the oil spill incident. These, together with the changes in species composition may be attributed to the immediate impact of the oil spill.

Recovery can only be validated with a continuous monitoring of the macrobenthic infauna both inside and outside TINMAR. This is because 
Table 6.Comparison of mean species richness of macrobenthic infauna in Guimaras Island, October 2006

\begin{tabular}{|c|c|c|c|c|c|}
\hline Station & Cabano & Alegria & Igang & Lawi & TINMAR \\
\hline 1 & 27 & 12 & 11 & 8 & -- \\
\hline 2 & 10 & 12 & 11 & 6 & --- \\
\hline 3 & 14 & 10 & & 11 & --- \\
\hline 10 & & & & & 20 \\
\hline 31 & & & & & 18 \\
\hline 33 & & & & & 13 \\
\hline 18 & & & & & 30 \\
\hline 21 & & & & & 32 \\
\hline 20 & & & & & 29 \\
\hline 9 & & & & & 21 \\
\hline 32 & & & & & 19 \\
\hline 12 & & & & & 32 \\
\hline 13 & & & & & 34 \\
\hline 14 & & & & & 33 \\
\hline 26 & & & & & 21 \\
\hline 27 & & & & & 6 \\
\hline 28 & & & & & 14 \\
\hline$n$ & 3 & 3 & 2 & 3 & 14 \\
\hline Mean & 17 & 11 & 11 & 8 & 23 \\
\hline $\mathrm{Sd}$ & 8.89 & 1.15 & 0.00 & 2.52 & 8.75 \\
\hline Median & 14 & 12 & 11 & 8 & 21 \\
\hline Max & 27 & 12 & 11 & 11 & 34 \\
\hline Min & 10 & 10 & 11 & 6 & 6 \\
\hline $\mathrm{F}$ (variance) & 23.03 & \multicolumn{3}{|c|}{ on log-transformed data } & \\
\hline$P(F<=f)$ one tail & 0.042 & & & & \\
\hline
\end{tabular}

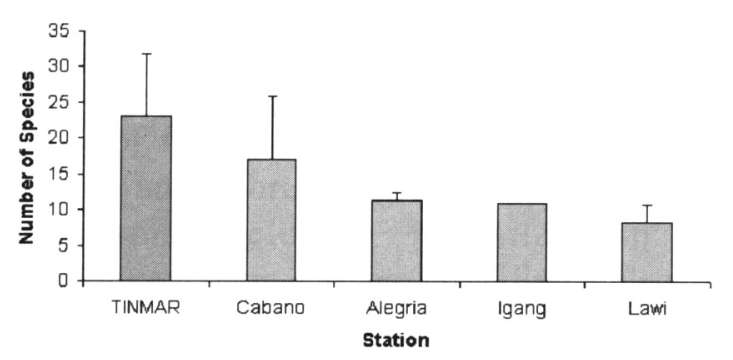

Figure 8. Spatial distribution of mean species richness of macrobenthic infauna in Guimaras Island, October 2006

the limits of natural variability are defined by combined short- and long-term fluctuations. The time it takes for recovery depends on many factors including the type of oil, the extent of initial contamination, the habitat type, weather conditions, latitude, and the assemblages of species. From a continuous monitoring program, more insights will be derived on which of these factors exert the strongest influence on the recovery of these communities.
Acknowledgments. This study was funded by a UPV in-house research program "Rapid Assessment of Environmental and Social Effects of the Solar Oil Spill in Southern Guimaras, Philippines - Program A. Biological and Physico-chemical Assessment of the Oil-Impacted Marine Habitats in Southern Guimaras". We thank the following for their laboratory and field assistance: Laureen Manalo, Rocille Palla, Pacifico Beldia II, Genibeth Genito, Annie Mequila, Fenelyn Nabuab, \& August Santillan. Dr. Wilfredo Campos, Head of the Bio-physical Team of the program helped organize the activities of this study.

\section{REFERENCES}

Barnes, R.S.K., and R.N. Hughes. 1982. An Introduction to Marine Ecology. Blackwell Sci. Publ., Oxford, UP: 339 p.

Conan, G. 1982. The long-term effects of the Amoco Cadiz oil spill. Phil. Trans. R. Soc. London B. 297: 323-333. 
Fauchald, K. 1977. The Polychaete Worms. Definition and keys to the Orders, Families, and Genera. Natural History Museum of Los Angeles County. The Allan Hancock Foundation, University of Southern California Science Series. 28, pp. 1-188.

Fauvel, P. 1953. Annelida: Polycheta. The Fauna of India including Pakistan, Ceylon, Burma and Malaya. Allahabad: 507p.

Ganning, B., D.J. Reish, and D. Straughan. 1984. Recovery and rexstoration of rocky shores, sandy beaches, tidal flats and shallow subtidal bottoms impacted by oil spills. Restoration of Habitats Impacted by Oil Spills. Boston, Butterworth Publisher.

Grassle, J.F., and J.P. Grassle. 1974. Opportunistic life histories and genetic systems in marine benthic polychaetes. Journal of Marine Research, 32: 253284.

Gray, J.S. 1981. The ecology of marine sediments. Cambridge Univ. Press, Cambridge, UK: 185p.

Gray, J.S., and T.H. Pearson. 1982. Objective selection of sensitive species indicative of pollution-induced change in benthic communities: Comparative methodology. Marine Ecology Progress Series, 9: 111-119.

Hall, S.J. 1994. Physical disturbance and marine benthic communities: Life in unconsolidated sediments. Ocean Marine Biology: An annual rev., 32: 179239.

Higgins, R.P., and H. Thiel. 1988. Introduction to the study of meiofauna. Smithsonian Institution Press, Wash. D.C.
Kingston, P.F., I.M.T. Dixon, S. Hamilton, and D.C Moore. 1995. The impact of the Braer oil spill on the macrobenthic infauna of the sediments off the Shetland Islands. Marine Pollution Bulletin, 30: 45-459.

Narida-Nacionales, E.B., and W.L. Campos. 2004. Macrobenthic assemblages in Taklong Island National Marine Reserve, Southern Guimaras. UPV Journal of Natural Sciences, 9(1): 30-44.

NOAA. 1997. Integrating physical and biological studies of recovery from the Exxon Valdez oil spill. NOAA Tech. Memo. NOS ORCA 114.

NOAA. 1998. Oil spill impacts and the biological basis for response guidance: An applied synthesis of research on three subarctic intertidal communities. NOAA Tech. Memo. NOS ORCA 125, Seattle, Wash.

Pearson, T.H. and R. Rosenberg. 1978. Macrobenthic succession in relation to organic enrichment and pollution of the environment. Ocean Marine Biology Annual Review, 16:229-311.

Pearson, W.H., D.L. Woodruff, P.C. Sugarman, and B.L. Olla. 1981. Effects of oiled sediment on predation on the littleneck clam, Protothaca staminea, by the Dungeness crab, Cancer magister. Estuarine Coastal \& Shelf Science, 13: 445-454.

Sanborn, H. R. 1977. Effects of petroleum on ecosystems. Chap. 6. In: Malins, D.C. (ed.). Effects of Petroleum on Arctic and Subarctic Marine Organisms, Vol. II. Biological Effects. Academic Press Inc., New York: 337-352.

Suchanek, T.H. 1993. Oil impacts on marine invertebrate populations and communities. American Zoologist, 33(6): 510-523. 